\title{
Effects of Xanthine Derivatives on Phosphatidylcholine Secretion in Rat Type II Pneumocytes in the Presence of Activated Eosinophils
}

\author{
Manabu Okumura ${ }^{1,2}$, Hirofumi Kai ${ }^{2}$, Shinya Shinozawa ${ }^{1}$, Yoichiro Isohama ${ }^{2}$, Kazuo Takahama ${ }^{2}$ and Takeshi Miyata ${ }^{2, *}$ \\ 'Department of Pharmacy, Miyazaki Medical College, 5200 Kihara, Kiyotake-cho, Miyazaki 889-16, Japan \\ ${ }^{2}$ Department of Pharmacological Sciences, Faculty of Pharmaceutical Sciences, Kumamoto University, 5-1 Oe-honmachi, Kumamoto 862, Japan
}

Received March 17, 1997 Accepted October 1, 1997

\begin{abstract}
We have previously reported that activated eosinophils enhanced the phosphatidylcholine (PC) secretion in type II pneumocytes. In this study, we have determined whether xanthine derivatives affect the PC secretion increased by activated eosinophils. Theophylline enhanced the increased PC secretion at $10^{-5} \mathrm{M}$. 8-Phenyltheophylline dose-dependently enhanced the PC secretion. The enhanced secretion by either theophylline at $10^{-5} \mathrm{M}$ or 8-phenyltheophylline was suppressed by superoxide dismutase in combination with catalase. Pentoxifylline did not enhance the PC secretion increased by activated eosinophils, although it increased the PC secretion by itself. The PC secretion increased by theophylline at $10^{-3} \mathrm{M}$ or pentoxifylline was not suppressed by superoxide dismutase in combination with catalase. The present results suggest that xanthine derivatives increased the PC secretion in the co-culture of type II pneumocytes and activated eosinophils possibly through the inhibition of phosphodiesterases or the antagonism of adenosine receptors of the eosinophils.
\end{abstract}

Keywords: Pneumocyte (type II), Phosphatidylcholine secretion, Eosinophil, Superoxide anion, Xanthine derivative

Xanthine derivatives have been widely used in the treatment of asthma and inhibit the late response to an inhaled allergen, suggesting that the drugs have effects on the inflammatory response $(1,2)$. However, it has been reported that theophylline had no effect on bronchial hyperresponsiveness in asthmatic subjects, which may be related to eosinophil recruitment and its activation (3). The bronchial hyperresponsiveness is suppressed by glucocorticoid, cyclooxygenase inhibitor and thromboxane inhibitor $(4,5)$, which suggests that eicosanoids such as prostaglandins, leukotriene and thromboxane $\mathrm{A}_{2}$ play important roles to induce the pathogenesis. We have speculated that the reason for the ineffectiveness of theophylline may be that theophylline at clinical concentrations has a potential to increase the level of oxygen free radicals. The speculation is supported by the observation that theophylline increased opsonized zymosan-stimulated oxygen-free radical release from guinea pig and human eosinophilia (6). Eosinophils infiltrated into the lung release many cytotoxic proteins, leukotrienes, platelet-activating factor, and various oxygen-derived

* To whom correspondence should be addressed. toxic metabolites such as superoxide anions, $\mathrm{H}_{2} \mathrm{O}_{2}$, and hydroxy radicals $(7,8)$. The release of cytotoxic proteins and other mediators from eosinophils causes desquamation and damage to respiratory epithelial cells (9).

The type II pneumocytes produce pulmonary surfactant to maintain normal lung functions (10). Pulmonary surfactant, which is composed of phospholipids and apoproteins, lowers the surface tension at the air-liquid interface in the lung and provides for alveolar stability. In addition to the vital role, pulmonary surfactant also plays an important role to facilitate and maintain airway mucociliary clearance $(11-18)$. We have shown that activated eosinophils increase the secretion of phosphatidylcholine (PC), the predominant component of pulmonary surfactant, in a primary culture of type II pneumocytes (19). The increase of PC secretion was mediated by superoxide anions released from activated eosinophils. In addition, we have reported that xanthine derivatives also increased PC secretion possibly through cAMP-dependent and cAMP-independent pathways in type II pneumocytes (20). From pathophysiological and clinical points of view, it seems important to investigate how xanthine derivatives affect PC secretion in type II pneumocytes 
in the presence of activated eosinophils. Therefore, we have examined whether theophylline, 8-phenyltheophylline and pentoxifylline affect the $\mathrm{PC}$ secretion in the coculture of type II pneumocytes and activated eosinophils. We used these drugs because their properties are advantageous for the present studies. Theophylline has multiple effects including an inhibition of phosphodiesterases (cAMP-phosphodiesterase (21) or cGMP-phosphodiesterase (22)), an antagonism of adenosine receptors (23), and an alteration of intracellular calcium mobilization (2). 8-Phenyltheophylline is an adenosine receptor antagonist that does not inhibit phosphodiesterase (24), and pentoxifylline is a phosphodiesterase inhibitor without an adenosine receptor antagonistic activity $(25,26)$.

\section{MATERIALS AND METHODS}

\section{Primary rat type II pneumocyte culture}

Type II pneumocytes were isolated from the lungs of adult specific-pathogen-free male Wistar rats $(180-200 \mathrm{~g})$ according to the method of Dobbs et al. (27). This method routinely yielded $10^{7}$ cells per rat. The cells were suspended at $10^{6}$ cells $/ \mathrm{ml}$ in Dulbecco's modified Eagle's medium supplemented with $10 \%$ fetal bovine serum, $74 \mathrm{kBq} / \mathrm{ml}$ [methyl ${ }^{3} \mathrm{H}$ ]choline (specific activity, 3.0 $\mathrm{TBq} / \mathrm{mmol}$ ), $100 \mathrm{units} / \mathrm{ml}$ penicillin and $100 \mu \mathrm{g} / \mathrm{ml}$ streptomycin, plated on 24-well tissue culture plate (Falcon 3047 ), and then cultured at $37^{\circ} \mathrm{C}$ in $5 \% \mathrm{CO}_{2}$-air for $18 \mathrm{hr}$. Non-adherent cells were removed from the wells by washing before the assay. For cellular identification, the sample was stained with a tannic acid and polychrome stain (28) and alkaline phosphatase stain (29). The purity of the type II pneumocytes monolayer was $95 \pm 3 \%$ (mean \pm S.E., $n=8$ ). The viability of type II pneumocytes was $98 \pm 2 \%$ (mean \pm S.E., $n=8$ ) as judged by the trypan blue exclusion test.

\section{Eosinophil isolation and opsonized zymosan preparation}

Eosinophils were isolated from peritoneal exudates of Hartley guinea pig by a modification of the method described by Pincus (30). Briefly, peritoneal eosinophilrich exudates were produced by a weekly intraperitoneal injection of 7,500 units $/ \mathrm{ml}$ of polymyxin B sulfate for at least 8 weeks. Fifty milliliters of Hank's balanced salt solution containing 20 units $/ \mathrm{ml}$ sodium heparin was injected intraperitoneally the next day after the last injection of polymyxin B sulfate. The abdomen was massaged gently, and the fluid was collected. The fluid was fractionated by centrifugation through solutions of Nycodenz. The purified fraction of eosinophils was collected from the interface between 1.088 and $1.098 \mathrm{~g} / \mathrm{ml}$ in the gradient. The eosinophils were $95 \%$ pure as determined in Litt's stained smears. To prepare opsonized zymosan, zymosan A in Hank's balanced salt solution was boiled, washed, and then incubated with fresh rat serum for $30 \mathrm{~min}$ at $37^{\circ} \mathrm{C}$. After centrifugation and washing 4 times, opsonized zymosan was suspended in Hank's balanced salt solution at a concentration of $10 \mathrm{mg} / \mathrm{ml}$ and stored at $-70^{\circ} \mathrm{C}$ until the use.

\section{Metabolic labeling of $P C$ and treatment of cultures}

Secretion of PC by cultured type II pneumocytes was determined as follows: The cells were rinsed with fresh serum- and antibiotics-free medium to remove [methyl$\left.{ }^{3} \mathrm{H}\right]$ choline and unattached cells. Eosinophils, opsonized zymosan and various agents (theophylline, 8-phenyltheophylline, pentoxifylline) were added $30 \mathrm{~min}$ after the rinse and then the incubation was performed for $90 \mathrm{~min}$. At the end of the incubation period, the medium was aspirated off, the cells were lysed with $2 \mathrm{ml}$ ice-cold $0.05 \%$ Triton X-100 solution and lipids were extracted from both the cells and the medium with chloroform and methanol $(2: 1, \mathrm{v} / \mathrm{v})$. PC was separated from the other phospholipids by thin-layer chromatography (31), and its radioactivity was measured with a liquid scintillation counter after an addition of $5 \mathrm{ml}$ Aquasol II to each sample. Secretion was expressed as the amount of $\left[{ }^{3} \mathrm{H}\right] \mathrm{PC}$ in the medium after the 90 -min incubation, as a percentage of that in cells plus medium. $\left[{ }^{3} \mathrm{H}\right] \mathrm{PC}$ secretion for $90 \mathrm{~min}$ was $0.69 \pm 0.06 \%$ (mean \pm S.E., $n=20$ ) in control culture.

\section{Measurement of superoxide anions generation}

The generation of superoxide anions was measured by the reduction of horse heart ferricytochrome $c$ (32). Isolated eosinophils $\left(10^{5}\right.$ cells $\left./ \mathrm{ml}\right)$ were preincubated with a drug (theophylline, 8-phenyltheophylline or pentoxifylline) at $37^{\circ} \mathrm{C}$ for $15 \mathrm{~min}$, and $10 \mu \mathrm{M}$ cytochrome $\mathrm{c}$ and 100 $\mu \mathrm{M}$ opsonized zymosan were added. The eosinophils were incubated for $90 \mathrm{~min}$. The medium was collected and centrifuged at $400 \times \mathrm{g}$ for $5 \mathrm{~min}$ at $4{ }^{\circ} \mathrm{C}$, and the supernatant was removed. Light absorbance at $550 \mathrm{~nm}$ was determined in a spectrophotometer. The generation was expressed as a percentage of the absorbance against that of control.

\section{Detection of cell membrane damage and chemicals}

The presence or absence of cytoplasmic leakage due to cell membrane damage following the treatment was determined by measuring lactate dehydrogenase (LDH) activity in the culture medium with a commercial LDH assay kit (Nippon Shoji Co., Ltd, Osaka). The LDH activity released into the medium did not exceed $1 \%$ of the total cell content in all experiments (data not shown).

The rats and guinea pigs were purchased from Kyudo Farm (Fukuoka), tissue culture medium from Nissui Pharmaceutical Co., Ltd. (Tokyo) and fetal bovine serum from JRH Bioscience (Lenexa, KS, USA). [Methyl- 
$\left.{ }^{3} \mathrm{H}\right]$ choline and Aquasol II were obtained from NEN Research Products (Boston, MA, USA). Other reagents and biochemicals were from Sigma Chemicals Co. (St. Louis, MO, USA).

\section{Statistics}

PC secretion values and superoxide anions generation for each group were expressed as means \pm S.E. The difference among groups was assessed by Duncan's multiple range test (a non-parametric test). $\mathrm{P}>0.05$ was considered not significantly different.

\section{RESULTS}

Generation of superoxide anions from activated eosinophils

The generation of superoxide anions from eosinophils was increased by opsonized zymosan, and the increase was dependent on the number of eosinophils $\left(10^{4}\right.$ to $10^{6}$ cells $/ \mathrm{ml}$ ). The sufficient number of eosinophils to increase the $\left[{ }^{3} \mathrm{H}\right] \mathrm{PC}$ secretion in rat type II pneumocytes was $10^{5}$ cells $/ \mathrm{ml}$, and the increase was similar to the result in our previous report (19). Addition of superoxide dismutase in combination with catalase completely suppressed the increased generation of superoxide anions (Fig. 1). These results indicated that isolated eosinophils were intact in their functions.

Effects of xanthine derivatives on superoxide anions generation from eosinophils stimulated by opsonized zymosan

Theophylline showed a biphasic action on superoxide

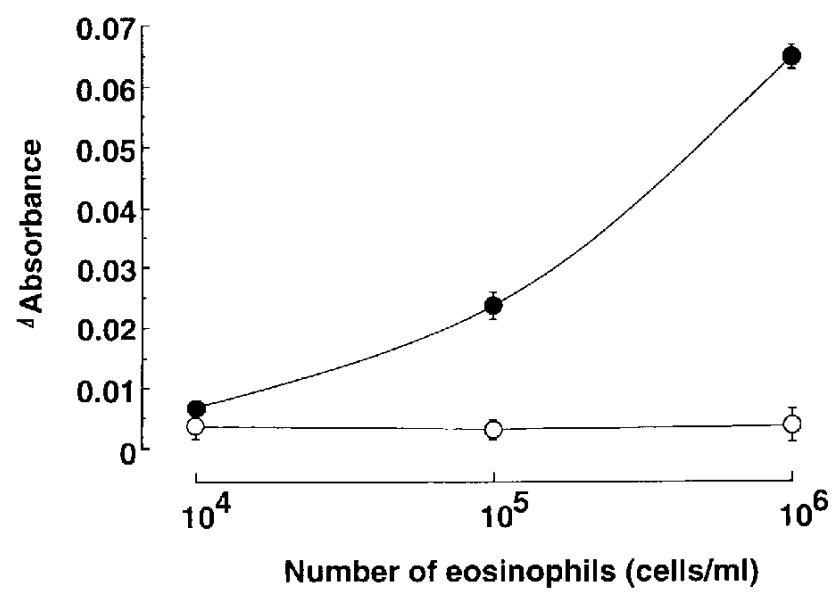

Fig. 1. Generation of superoxide anions from opsonized zymosan activated eosinophils alone (O) or with superoxide dismutase $(2$ units $/ \mathrm{ml})$ and catalase $(1000$ units $/ \mathrm{ml})(\bigcirc)$. The values of superoxide anion generation were expressed as absorbance at $550 \mathrm{~nm}$ of reduced cytochrome $c$ formed from ferricytochrome $c$. Data are each the mean \pm S.E. of 8 experiments.

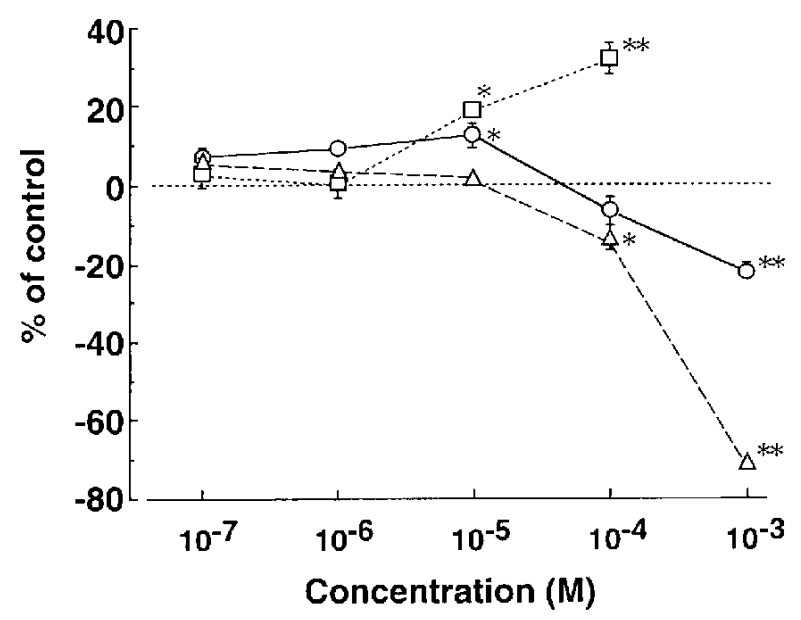

Fig. 2. Effects of xanthine derivatives on superoxide anions generation in activated cosinophils. Eosinophils were preincubated with the indicated concentration of theophylline ( $O$ ), 8-phenyltheophylline $(\square)$ and pentoxifylline $(\triangle)$ before an addition of opsonized zymosan. Data are each the mean \pm S.E. of 6 experiments. ${ }^{*}$ and ${ }^{* *}$ : Significant at $P<0.05$ and $P<0.01$ vs control, respectively.

anions generation from eosinophils stimulated by opsonized zymosan (Fig. 2). Theophylline increased the superoxide anions generation at concentrations of $10^{-6}$ and $10^{-5} \mathrm{M}$, whereas it inhibited the generation at concentrations of $10^{-4}$ and $10^{-3} \mathrm{M}$. In contrast, 8-phenyltheophylline increased the superoxide anions generation, whereas pentoxifylline inhibited it dose-dependently. A significant potentiation of the generation by 8 -phenyltheophylline occurred at concentrations of $10^{-5}$ to $10^{-4} \mathrm{M}$.

Effects of xanthine derivatives on the $P C$ secretion increased by activated eosinophils in primary culture of rat type II pneumocytes

Theophylline increased the PC secretion in rat type II pneumocytes dose-dependently with the doses higher than $10^{-4} \mathrm{M}$ and the result was similar to that in our previous report (20). Theophylline at $10^{-5} \mathrm{M}$ or lower concentrations did not affect the secretion. However, theophylline at $10^{-5} \mathrm{M}$ enhanced the PC secretion increased by activated eosinophils (Fig. 3). The enhanced secretion was suppressed by superoxide dismutase in combination with catalase. However, superoxide dismutase and catalase had no effect on the enhanced secretion by theophylline at $10^{-3} \mathrm{M}$ in the presence of activated eosinophils.

Whereas 8-phenyltheophylline had no effect on the PC secretion in type II pneumocytes, 8-phenyltheophylline dose-dependently enhanced the PC secretion increased by activated eosinophils (Fig. 4). The enhanced secretion by 8-phenyltheophylline was suppressed by superoxide dismutase in combination with catalase, and it was completely suppressed by further addition of adenosine 


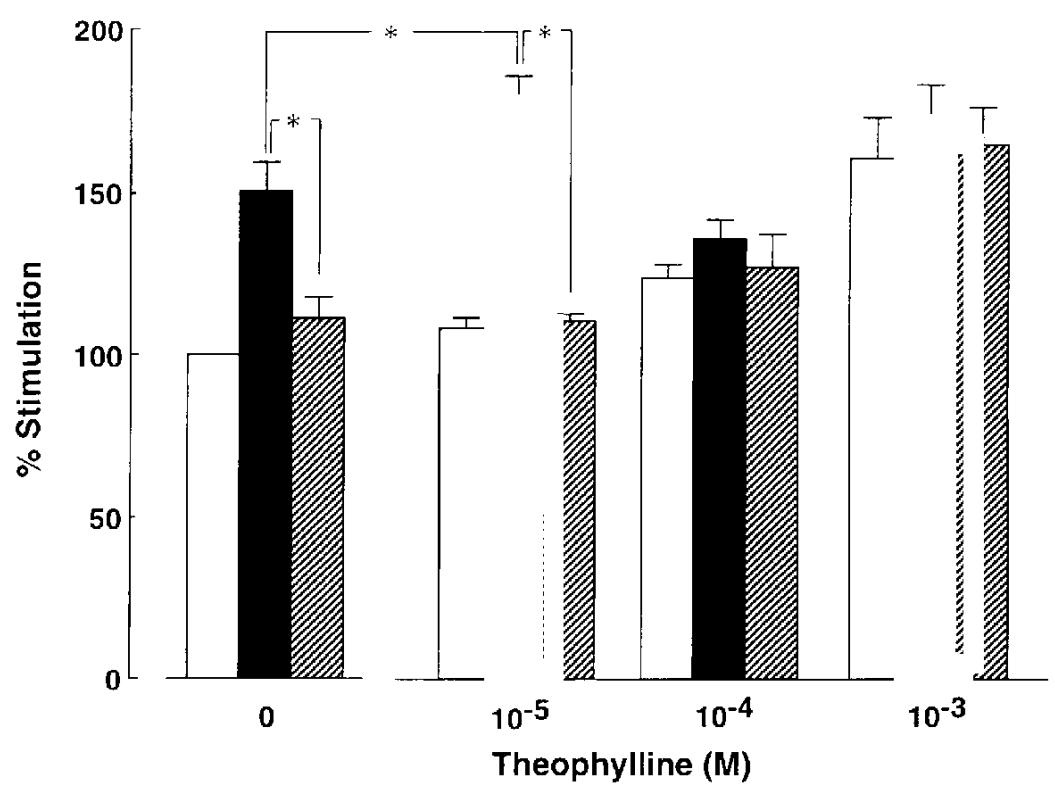

Fig. 3. Effect of theophylline on the PC secretion incresed by activated eosinophils in type II pneumocytes. Type II pneumocytes were incubated with the indicated concentrations of theophylline alone (open bars), theophylline with activated eosinophils (solid bars), or theophylline with activated eosinophils in the presence of superoxide dismutase ( 2 units $/ \mathrm{ml}$ ) and catalase (1000 units $/ \mathrm{ml}$ ) (hatched bars). Data are each the mean \pm S.E. of 5 experiments. ${ }^{*}$ : Significant at $\mathbf{P}<0.01$.

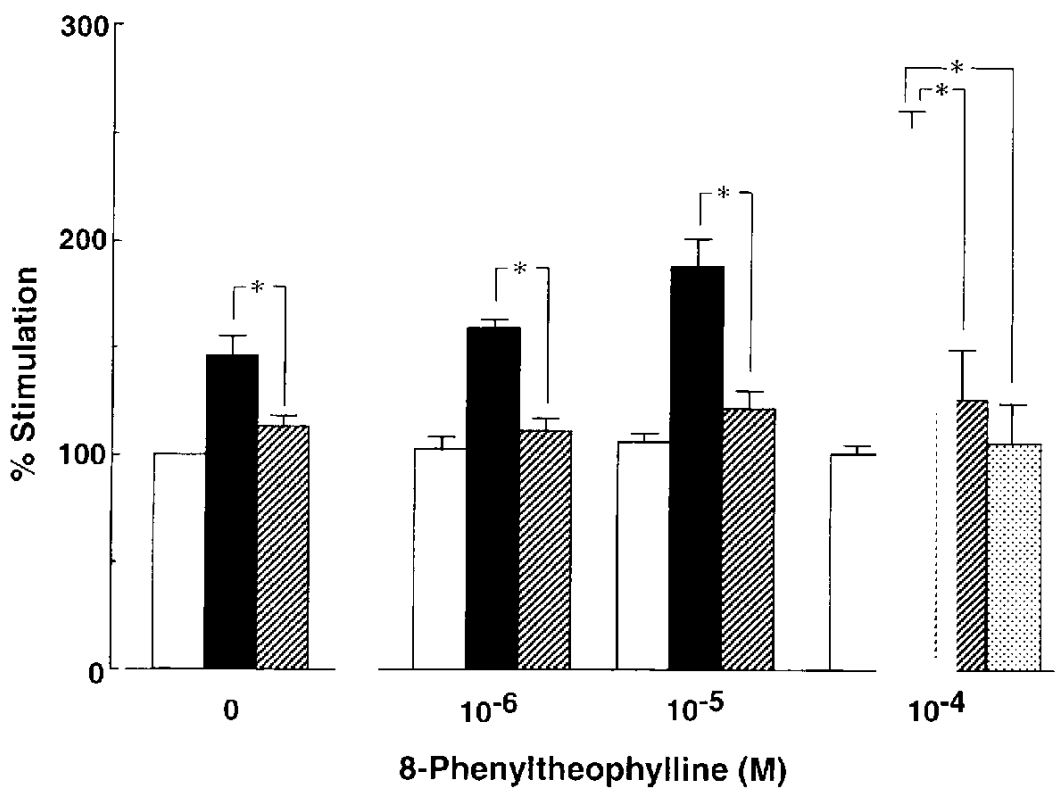

Fig. 4. Effect of 8-phenyltheophylline on the PC secretion increased by activated eosinophils in type II pneumocytes. Type II pneumocytes were incubated with the indicated concentrations of 8-phenyltheophylline alone (open bars), 8-phenyltheophylline with activated eosinophils (solid bars), or 8-phenyltheophylline with activated eosinophils in the presence of superoxide dismutase ( 2 units $/ \mathrm{ml})$ and catalase $(1000$ units $/ \mathrm{ml})$ (hatched bars), and further addition of adenosine deaminase $(1 \mathrm{units} / \mathrm{ml})$ (stippled bar). Data are each the mean \pm S.E. of 5 experiments. ${ }^{*}$ : Significant at $\mathrm{P}<0.01$.

\section{deaminase.}

Pentoxifylline increased the PC secretion in type II pneumocytes. However, pentoxifylline did not enhance the PC secretion increased by activated eosinophils (Fig. 5). The PC secretion increased by pentoxifylline was not suppressed by superoxide dismutase in combination with 


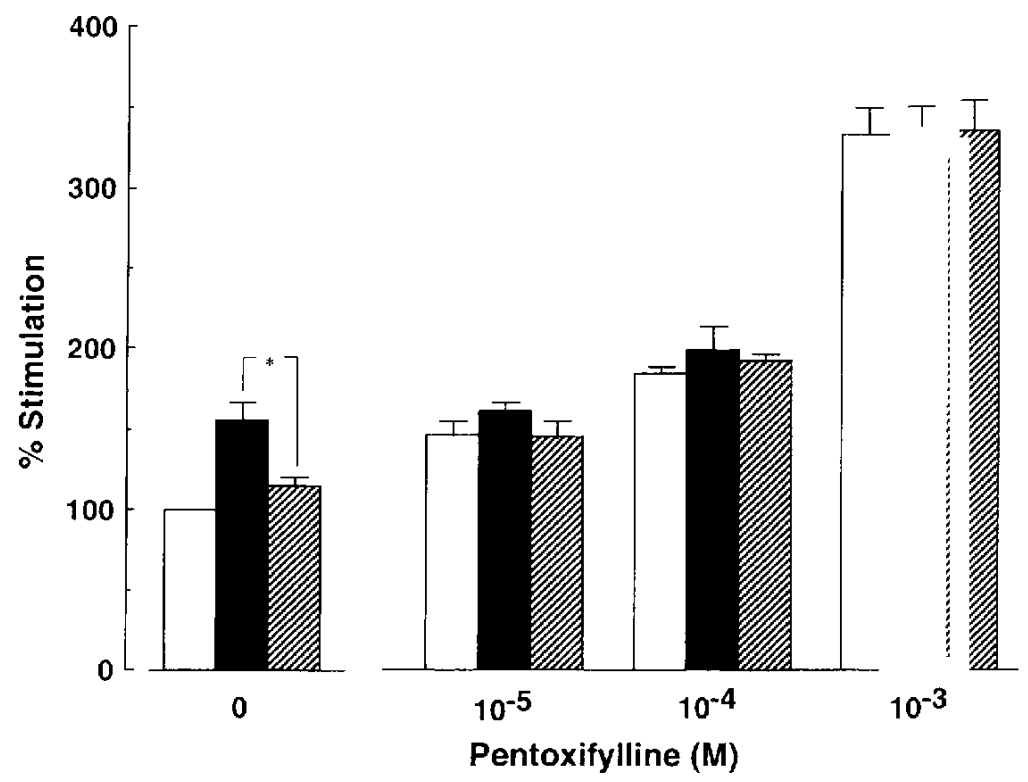

Fig. 5. Effect of pentoxifylline on the PC secretion increased by activated eosinophils in type II pneumocytes. Type II pneumocytes were incubated with the indicated concentrations of pentoxifylline alone (open bars), pentoxifylline with activated eosinophils (solid bars), or pentoxifylline with activated eosinophils in the presence of superoxide dismutase ( 2 units $/ \mathrm{ml})$ and catalase $\left(1000\right.$ units $/ \mathrm{ml}$ ) (hatched bars). Data are each the mean \pm S.E. of 5 experiments. ${ }^{*}$ : Significant at $\mathbf{P}<0.01$.

catalase.

\section{DISCUSSION}

Eosinophils infiltrated into the lung are activated in subjects with asthma. The infiltration and activation are induced by chemical mediators, including PAF and histamine released from mast cells stimulated by allergens inhalation. Therefore, it seems important to obtain information on the influence of eosinophils on the secretion of pulmonary surfactant. We previously reported that the activated eosinophils increased the PC secretion in type II pneumocytes, and the increase was suppressed by superoxide dismutase and catalase (19). The results suggested that activated eosinophils stimulated the secretion of pulmonary surfactant, at least in part, through superoxide anions. The pulmonary surfactant secretion increased by activated eosinophils may be a kind of defense mechanism to attenuate oxidative cellular damages caused by oxidant radicals released from activated eosinophils, because pulmonary surfactant is known to be an inert material against oxidative reaction (33). The increased pulmonary surfactant also may play important roles to facilitate and maintain airway mucociliary clearance (11-18). Hence, the study of the effect of drugs on the PC secretion in the presence of eosinophils is important because eosinophils are regarded as potent proinflammatory cells with considerable tissue-injuring capacity, possibly casually involved in the development of lung dis- eases such as asthma (34-36).

In the present study, we found that xanthine derivatives affected the PC secretion increased by activated eosinophils in rat type II pneumocytes. Theophylline showed a biphasic action on superoxide anions generation from activated eosinophils. There was a biphasic action of theophylline in the effect on the PC secretion in the co-culture of type II pneumocytes and activated eosinophils. We have proposed a hypothesis whereby theophylline enhanced the PC secretion increased by activated eosinophils possibly through two distinct mechanisms (Fig. 6); one is the antagonism of adenosine receptors on the eosinophils which increase the release of superoxide anions, because exogenously applied adenosine suppressed the superoxide anions generation from activated eosinophils (6). Thereby, the superoxide anions induce PC secretion in the type II pneumocytes. The other mechanism is an inhibition of phosphodiesterase in the eosinophils as well as the pneumocytes. The inhibition of phosphodiesterase in eosinophils decreases the release of superoxide anions through the increase of intracellular cAMP. Thus, the PC secretion increased by superoxide anions is suppressed by theophylline. At the same time, however, the increase of intracellular cAMP in the type II pneumocytes induces the PC secretion. The ineffectiveness of theophylline at $10^{-4} \mathrm{M}$ may be due to a balanced situation between the extent of the suppression of the PC secretion increased by activated eosinophils and the extent of the increase of PC secretion through intracellular 


\section{A) No xanthines}

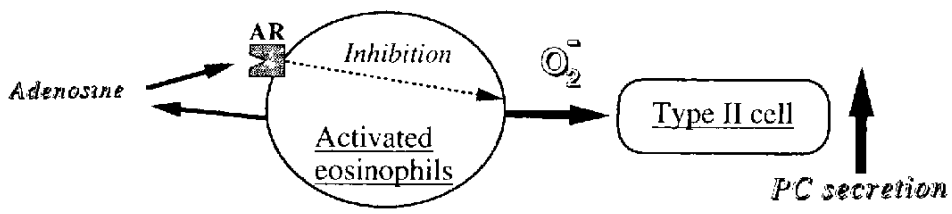

B) Theophylline (low conc.) \& 8-Phenyltheophylline

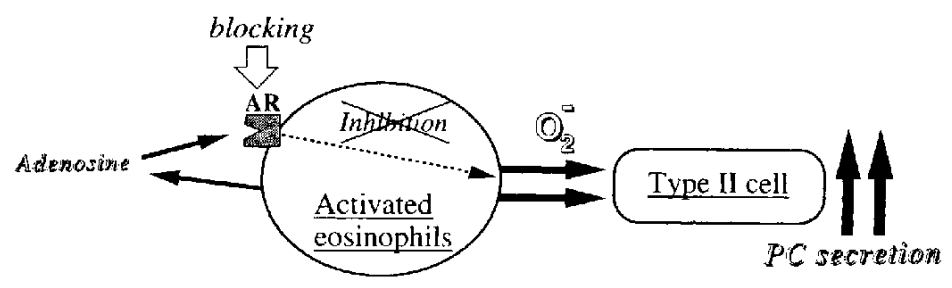

C) Theophylline (high conc.) \& Pentoxifylline
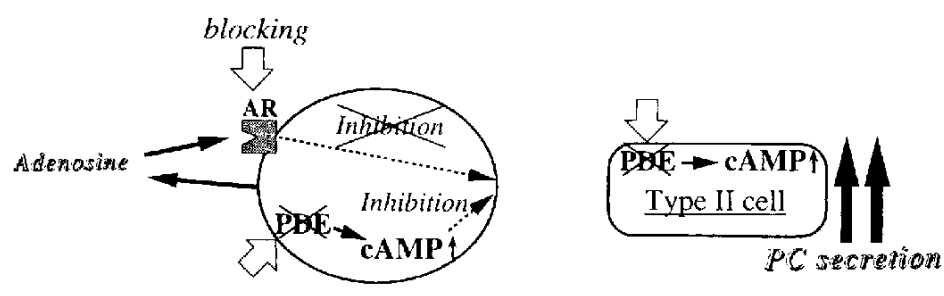

Activated eosinophils

Fig. 6. Possible mechanisms of action of xanthine derivatives on the PC secretion in type II pneumocytes in the presence of activated eosinophils. A: Activated eosinophils generate superoxide anions $\left(\mathrm{O}_{2}{ }^{-}\right)$to induce $\mathrm{PC}$ secretion in type II pneumocytes. Endogenous adenosine may be released from eosinophils by itself to suppress superoxide anions generation through its own adenosine receptor (AR) in eosinophils. B: Theophylline at $10^{-5} \mathrm{M}$ and 8-phenyltheophylline antagonize adenosine receptors on the eosinophils, which increase the release of superoxide anions, because exogenously applied adenosine suppressed the superoxide anion generation from activated eosinophils (6). Thereby, the superoxide anions induce PC secretion in the pneumocytes. An open arrow indicates the site of action of xanthine derivatives. C: Theophylline at $10^{-3} \mathrm{M}$ and pentoxyfylline inhibit phosphodiesterases (PDE) in the eosinophils as well as the pneumocytes. The inhibition of phosphodiesterases in eosinophils decrease the release of superoxide anions through the increase of intracellular cAMP. Thus, the PC secretion increased by superoxide anions is suppressed by theophylline. At the same time, however, the increase of intracellular cAMP in the type II pneumocytes induces the PC secretion. Open arrows indicate the sites of action of xanthine derivatives.

cAMP in type II pneumocytes. The balance seems important to determine the effect of theophylline on $\mathrm{PC}$ secretion by type II pneumocytes in the presence of activated eosinophils. The hypothesis we proposed here is supported by our findings on 8-phenyltheophylline and pentoxifylline.

8-Phenyltheophylline, which is an adenosine receptor antagonist and lacks a phosphodiesterase inhibitory action (24), had no direct effect on the PC secretion in rat type II pneumocytes, but it dose-dependently increased PC secretion in the presence of activated eosinophils. The increase of the PC secretion was reduced by superoxide dismutase in combination with catalase, and it was completely suppressed by the further addition of adenosine deaminase. These results indicated that 8-phenyltheophylline increased PC secretion through activated eosinophils. Therefore, the stimulatory effect of theophylline on superoxide anion generation at the low concentration may participate in the increase of PC secretion in rat type II pneumocytes in the presence of activated eosinophils, because theophylline has an antagonistic effect on adenosine receptors $(37,38)$. However, the source of endogenous adenosine has to be considered. It seems that endogenous adenosine is released from eosinophils by 
themselves to control superoxide anions generation through its own adenosine receptors in eosinophils, although it remains unclear to date.

It is known that pentoxifylline increases intracellular cAMP concentrations and the PC secretion in the type II pneumocytes (20) and that pentoxifylline decreases oxygen radicals release in polymorphonuclear leukocytes (39-41). The PC secretion increased by theophylline at the high concentration $\left(10^{-3} \mathrm{M}\right)$ as well as pentoxifylline was not suppressed by superoxide dismutase and catalase. These results suggested that the theophylline at the high concentration obviously increased the PC secretion in rat type II pneumocytes through the inhibition of phosphodiesterase of the pneumocytes, although it suppressed the PC secretion increased by superoxide anions from activated eosinophils. The effect of theophylline at $10^{-3} \mathrm{M}$ used here, however, may be out of consideration in a clinical situation, since the concentration seems to be higher than the plasma concentration of theophylline in clinical use.

In conclusion, we found that xanthine derivatives increased the PC secretion through two distinct mechanisms in the co-culture of type II pneumocytes and activated eosinophils.

\section{REFERENCES}

1 McFadden ER: Methylxanthines in the treatment of asthma: the rise, the fall, and the possible rise again. Ann Intern Med 115, $323-324$ (1991)

2 Barnes PJ and Pauwels RA: Theophylline in the management of asthma: time for reappraisal? Eur Respir J 7, 579- 591 (1994)

3 Dutoit JI, Salome CM and Woolcock AJ: Inhaled corticosteroids reduce the severity of bronchial hyperresponsiveness in asthma but oral theophylline does not. Am Rev Respir Dis 136, 1174- 1178 (1987)

4 Van-Hal PTW, Overbeek SE, Hoogsteden HC, Zijlstra FJ, Murphy K, Oosterhoff Y, Postma DS, Guz A and Smith SF: Eicosanoids and lipocortin- 1 in BAL fluid in asthma: effects of smoking and inhaled glucocorticoids. J Appl Physiol 81, $548-555$ (1996)

5 Fujimura $M$, Kamino $Y$, Kasahara K, Bando T, Hashimoto $T$ and Matsuda T: Prostanoids and cough response to capsaicin in asthma and chronic bronchitis. Eur Respir J 8, 1499-1505 (1995)

6 Yukawa T, Kroegel C, Chanez P, Dent G, Ukena D, Chung KF and Barnes PJ: Effect of theophylline and adenosine on eosinophil function. Am Rev Respir Dis 140, 327-333 (1989)

7 Gleich GJ, Loegering DA and Maldonado JE: Identification of a major basic protein in guinea pig eosinophil granules. J Exp Med 137, 1459-1471 (1973)

8 Gleich GJ and Adolphson CR: The eosinophilic leukocyte: Structure and function. Adv Immunol 39, 177-253 (1986)

9 Gleich GJ, Motojima S, Frigas E, Kephart GM, Fujisawa T and Kravis LP: The eosinophilic leukocyte and the pathology of fatal bronchial asthma: Evidence for pathologic heterogeneity. J Allergy Clin Immunol 80, 412-415 (1987)
10 Chander A and Fisher AB: Regulation of lung surfactant secretion. Am J Physiol 258, L241 - L253 (1990)

11 De Sanctis GT, Tomkiewicz RP, Rubin BK, Schurch S and King $M$ : Exogenous surfactant enhances mucociliary clearance in the anaesthetized dog. Eur Respir J 7, 1616-1621 (1994)

12 Allegra L, Bossi R and Braga PC: Influence of surfactant of mucociliary transport. Eur J Respir Dis 67, 71-76 (1985)

13 Morgenroth $\mathrm{K}$ and Bolz J: Morphological features of the interaction between mucus and surfactant on the bronchial mucosa. Respiration 47, 225-231 (1985)

14 Gehr P, Schurch S, Berthiaume Y, Im Hof V and Geiser M: Particle retention in airways by surfactant. J Aerosol Med 3, $27-43$ (1990)

15 Girod S, Galabert C, Pierrot D, Boissonnade MM, Zahm JM, Baszkin A and Puchelle E: Role of phospholipid lining on respiratory mucus clearance by cough. J Appl Physiol 71, 2262-2266 (1991)

16 Rubin BK, Ramirez $\mathrm{O}$ and King M: The role of mucus rheology and transport in neonatal respiratory distress syndrome and the effect of surfactant therapy. Chest 101, 1080-1085 (1992)

17 Schurch S, Gehr P, Im Hof V, Geiser M and Green FHY: Surfactant displaces particles toward the epithelium in airways and alveoli. Respir Physiol 80, 17-32 (1990)

18 Kai H, Saito M, Furusawa K, Oda Y, Okano Y, Takahama K and Miyata T: Protective effect of surface-active phospholipids against the acid-inducing inhibition of the tracheal mucociliary transport. Jpn J Pharmacol 49, 375-380 (1989)

19 Okumura M, Tsuruoka M, Isohama Y, Kai H, Takahama K and Miyata T: Activated eosinophils stimulate phosphatidylcholine secretion in primary culture of rat type II pneumocytes. Biochim Mol Biol Int 38, 569-575 (1996)

20 Okumura $\mathbf{M}$, Tsuruoka $\mathrm{M}$, Isohama $\mathrm{Y}$, Kai H, Takahama $\mathrm{K}$ and Miyata $T$ : Effects of xanthine derivatives on phosphatidylcholine secretion in primary culture of rat type II pneumocytes. Jpn J Pharmacol 67, 165-168 (1995)

21 Gilfillan AM and Rooney SA: Functional evidence for adenosine $A_{2}$ receptor regulation of phosphatidylcholine secretion in cultured type II pneumocytes. J Pharmacol Exp Ther 241, 907-914 (1987)

22 Gobran LI and Rooney SA: Adenosine $A_{1}$ receptor-mediated inhibition of surfactant secretion in rat type II pneumocytes. Am J Physiol 258, L45-L51 (1990)

23 Hughes PJ, Holgate ST and Church MK: Adenosine inhibits and potentiates IgE-dependent histamine release from human lung mast cells by an $\mathbf{A}_{2}$-purinoceptor mediated mechanism. Biochem Pharmacol 33, 3847-3852 (1984)

24 Rabe KF, Magnussen $H$ and Dent G: Theophylline and selective phosphodiesterase inhibitors as bronchodilators and smooth muscle relaxants. Eur Respir J 8, 637-642 (1995)

25 Kamphuis J, Smits $P$ and Thien T: Vascular effects of pentoxifylline in humans. J Cardiovasc Pharmacol 24, 648-654 (1994)

26 Corssmit EP, Romijn JA, Endert E and Sauerwein HP: Pentoxifylline inhibits basal glucose production in humans. J Appl Physiol 77, 2767-2772 (1994)

27 Dobbs LG, Gonzalez R and Williams MC: An improved method for isolating type II cells in high yield and purity. Am Rev Respir Dis 134, 141 - 145 (1986)

28 Mason RJ, Walker SR, Shields BA, Henson JE and Williams MC: Identification of rat alveolar type II epithelial cells with a tannic acid and polychrome stain. Am Rev Respir Dis 131, 
$786-788$ (1985)

29 Edelson JD, Shannon JM and Mason RJ: Alkaline phosphatase: marker of alveolar type II cell differentiation. Am Rev Respir Dis 138, $1268-1275$ (1988)

30 Pincus SH: Production of eosinophil-rich guinea pig peritoneal exudates. Blood 52, 127-134 (1978)

31 Miyata $T$, Kai H, Furusawa $K$, Nakamura $H$, Saito M, Okano $\mathrm{Y}$ and Takahama K: Secretomotor and mucolytic effects of mabuterol, a novel bronchodilator. Arch Int Pharmacodyn Ther 288, 147-160 (1987)

32 Babior BM, Kipnes RS and Curnutte JT: Biological defense mechanisms: The production by leukocytes of superoxide, a potential bactericidal agent. J Clin Invest 52, 741-744 (1973)

33 Hayakawa $\mathrm{H}$, Myrvik QN and St Clair RW: Pulmonary surfactant inhibits priming of rabbit alveolar macrophage. Evidence that surfactant suppresses the oxidative burst of alveolar macrophage in infant rabbits. Am Rev Respir Dis 140, 1390- 1397 (1989)

34 Monchy JGR, Kauffman HF, Venge P, Koeter GH, Jansen HM, Sluiter HJ and Vries K: Bronchoalveolar eosinophilia during allergen-induced late asthmatic reactions. Am Rev Respir Dis 131, 373-376 (1985)

35 Flavahan NA, Slifman NR, Gleich GJ and Vanhoutte PM: Human eosinophil major basic protein causes hyperreactivity of respiratory smooth muscle. Am Rev Respir Dis 138, 685688 (1988)

36 Wardlaw AJ, Dunnette S, Gleich GJ, Collins JV and Kay AB: Eosinophils and mast cells in bronchoalveolar lavage in subjects with mild asthma. Am Rev Respir Dis 137, 62-69 (1988)

37 Hussain T, Leigh JH and Mustafa SJ: Regulation of adenosine receptor function by theophylline in rat aorta. J Cardiovasc Pharmacol 24, 95-99 (1994)

38 Zarrindast MR and Shafaghi B: Effects of adenosine receptor agonists and antagonists on acquisition of passive avoidance learning. Eur J Pharmacol 256, 233-239 (1994)

39 Bessler $H$, Gilgal $R$, Djaldetti $M$ and Zahavi I: Effect of pentoxifylline on the phagocytic activity, cAMP levels, and superoxide anions production by monocytes and polymorphonuclear cells. J Leukoc Biol 40, 747-754 (1986)

40 Sato K, Stelzner TJ, O'Brien RF, Weil JV and Welsh $\mathrm{CH}$ : Pentoxifylline lessens the endotoxin-induced increase in albumin clearance across pulmonary artery endothelial monolayers with and without neutrophils. Am J Respir Cell Mol Biol 4, 219-227 (1991)

41 Simms HH and D'Amico R: Polymorphonuclear leukocyte dysregulation during the systemic inflammatory response syndrome. Blood 83, 1398-1407 (1994) 